\title{
Para uma estética da iconografia teatral?
}

\section{Vera Nobre Leitão}

\author{
José Carlos Alvarez (Coord.), \\ Rostos e poses, Lisboa, Museu Nacional \\ do Teatro, 2007, $132 \mathrm{pp}$.
}

Rostos e poses é o título do livro publicado, em Dezembro passado, pelo Museu Nacional do Teatro. Trata-se de uma selecção, da autoria de José Carlos Alvarez, director da instituição, de fotografias pertencentes ao espólio do Museu, tendo como base um critério cronológico: 0 objectivo foi agrupar retratos de actores nascidos até à segunda década do século XX. Organizados por ordem alfabética, figuram assim cinquenta e seis artistas nesta colecção, sendo apresentados dois retratos de cada um.

Embora a regra não se aplique em todos os casos, talvez por falta de material que possibilitasse a realização da empresa, podemos dizer que, para a larga maioria, se apresenta, em primeiro lugar, uma fotografia de rosto um close-up - ao qual se segue um retrato de corpo inteiro. Mesmo não se tratando de uma estrutura rígida, a escolha dominante parece, no entanto, justificar o título: rosto numa página, pose na seguinte, organização que, como veremos adiante, não é assim tão linear. Note-se porém que, a uma dada altura, este objectivo parece ter sido levado demasiadamente a sério, conduzindo à introdução de um retrato de Aura Abranches que não apresenta os critérios de qualidade patentes no resto das imagens - sendo, no entanto, o único caso.

Considerar a fotografia de rosto como um retrato à civil do actor e a fotografia em pose como uma imagem do artista em personagem parece ser uma visão um pouco redutora mas, em diversas situações, verificável. Esta hipótese não exclui, no entanto, a pose por detrás da fotografia de rosto à civil, como é o caso de Amélia Rey Colaço, de Francis ou de Erico Braga, entre outros. Na "Relação de imagens" feita no final da obra, é importante sublinhá-lo, não se encontram informações pormenorizadas relativas a todas as fotografias passiveis de serem assimiláveis a imagens de cena. Muito embora alguns dados não fossem certamente de fácil obtenção, ou confirmação, a sua ausência não deixa de indicar uma certa inclinação da obra no sentido de não sublinhar demasiado a fronteira entre o retrato de actor enquanto cidadão comum e o retrato de actor em personagem. Podemos talvez afirmar que a própria opção de separar a informação sobre a imagem da mesma caminha no mesmo sentido: José Carlos Alvarez escolhe, junto às fotografias, apenas indicar o nome do actor representado e, mesmo nos casos em que possui mais referências sobre o documento em causa, como por exemplo o título do

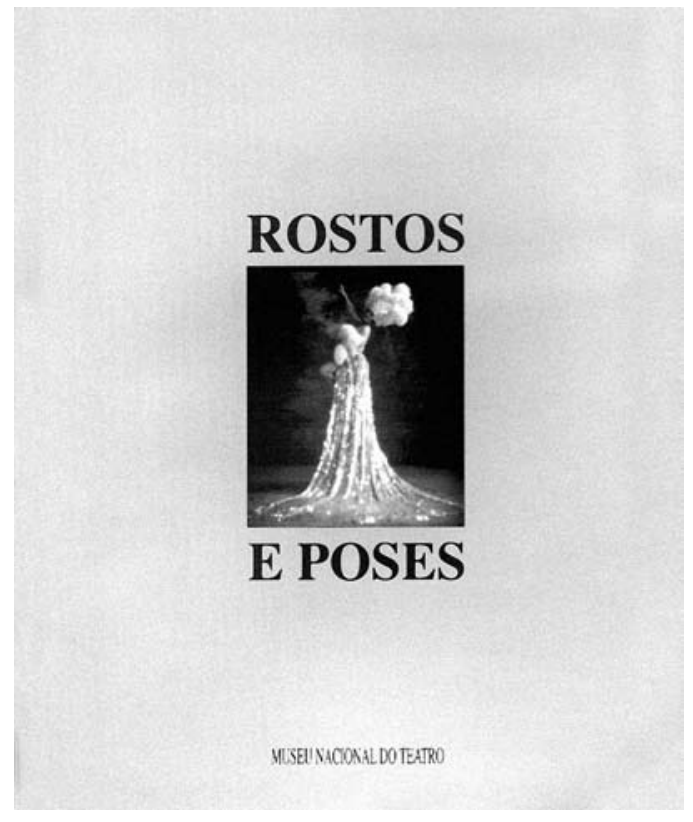

espectáculo, não deixa de as remeter para a dita "Relação de Imagens". Interessante opção, numa recolha de imagens, na medida em que ela permite ao utilizador comum manter a dúvida sobre a natureza de certos documentos, confundindo provavelmente $o$ actor com a personagem que representa para a objectiva. Esta mesma ambiguidade não deixa de ser irónica, e talvez mesmo produtiva, na medida em que permite compreender a encenação por detrás da arte fotográfica à época.

Nesta linha, a concepção de retrato de actor que parece transpirar de Rostos e poses é, de certa forma, híbrida: o artista está "presente" quer enquanto civil cuja profissão é ser actor, quer enquanto personagem porque, em última instância, a pose faz parte da estética fotográfica da altura, sobretudo tratando-se de fotografia de artistas:

\footnotetext{
0 retrato de actor exerceu também diferentes funções, sendo a primeira a de autopromoção, que já não tem como objectivo a imagem do homem que também é actor, mas sim a do actorintérprete, ou seja, a imagem do artista que é obra ao mesmo tempo. (Molinari 2002: 17, tradução minha)
}

Assim sendo, a fotografia assume a forma de uma folha em branco a colorir pelo actor de forma a escolher qual a imagem que quer guardar para a posteridade. Como muito bem aponta Carlos Alvarez no texto introdutório, talvez não existam duas artes tão antagónicas como o 


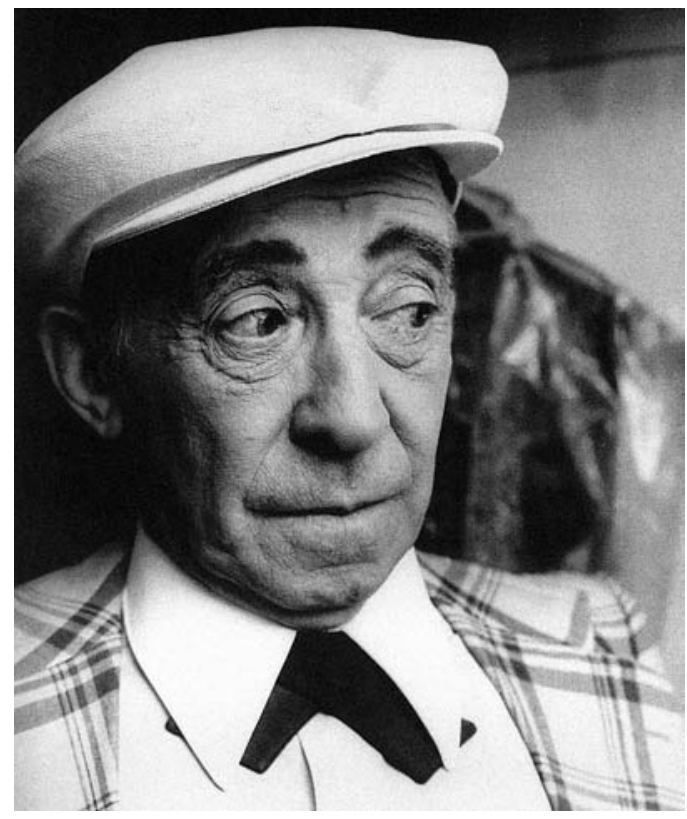

teatro ou a fotografia, mas essa separação parece criar o vácuo sobre o qual assentam as bases para uma arte outra que será a fotografia teatral. Qualquer que seja a personagem vestida pelo actor em estúdio perante a objectiva do fotógrafo, certo é que existe uma noção de personagem, de máscara, a colocar. E, mesmo se a "personagem" em causa é Alves da Cunha ou Ângela Pinto, a matéria-prima que Ihe dá vida tem conhecimento do poder da fotografia enquanto monumento, pelo que não deixa de o usar. São, assim, rostos de artistas face à possibilidade de dar um passo em frente no caminho para o que podemos chamar a "personalidade artística". Nada há de comum entre o retrato de Luísa Satanela e um retrato de rosto produzido nos nossos dias por uma qualquer máquina digital: antes de ter em conta o objecto a copiar, a fotografia teria que postular a noção de pose e de produção de uma imagem visual obrigatoriamente muito forte pela remodelação em curso dos códigos de representação vigentes noutras artes. A todo este processo não seria alheia a noção de glamour à qual faz referência o autor da compilação no seu prefácio. A este propósito, importa fazer referência a Barthes, no seu texto "O actor de Harcourt", no qual, com alguma ironia, nos fala sobre a importância do referido estúdio na construção da imagem do actor: "[l]mporta que sejamos tomados de perturbação ao descobrir suspensa da escadaria do teatro, como uma esfinge à entrada de um santuário, a imagem olímpica de

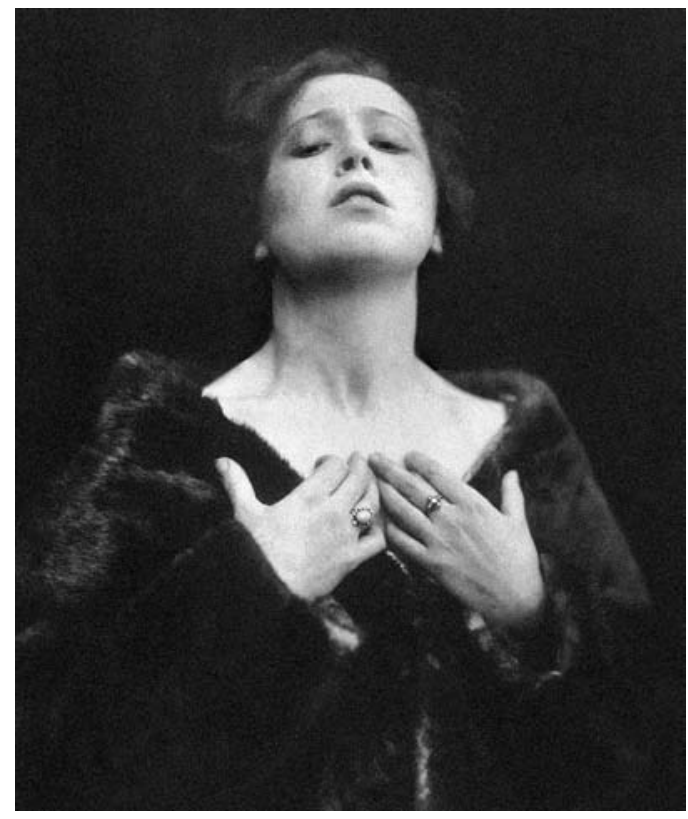

Eugénio Salvador, fot. Silva Nogueira / Fotografia Brasil, Arquivo Museu Nacional do Teatro.

Amélia Rey Colaço, fot. Photographia Londres, Arquivo Museu Nacional do Teatro.

um actor que despiu a pele de monstro agitado" (Barthes 1976: 19).

Se o fotografado buscava um "eu" outro construido quer através de uma personagem quer numa pose que simulasse uma imagem "teatral", um processo semelhante se passaria com o fotógrafo, na medida em que também este procurava um reconhecimento que resultava tanto maior quanto maior fosse a popularidade do artista retratado - esta busca mútua ilustra claramente a relação de simbiose que enuncia Laurence Senelick:

0 actor e o fotógrafo passaram a estar ligados numa relação simbiótica. 0 sucesso do fotógrafo estava dependente da sua capacidade de registar os notáveis da época, sobretudo actores e, mais especificamente, actrizes. 0 teatro, em contrapartida, estava cada vez mais dependente da fotografia para se publicitar.

(Senelick 2002: 323, tradução minha)

Prova deste mesmo fenómeno é o facto de, já neste pequeno corpus datado de imagens de actores, ser notória a reduzida lista de casas de fotografia às quais recorriam as personalidades que se faziam retratar com o objectivo de adquirir maior notoriedade ou de manter uma imagem já de si importante.

Nesta medida, não pode deixar de ser tida em conta a mediação, sublinhada por tantos estudiosos de iconografia teatral, sempre presente em qualquer 
documento fotográfico. Ora, em compilações como Rostos e poses, na qual o objecto fotografado é um actor, tratase de sublinhar uma construção que passa, num só negativo, pelo somatório das expectativas do actor, enquanto personagem, enquanto profissional ou ambos e pelas expectativas do fotógrafo, sendo igualmente importante ter em conta aquilo a que podemos chamar a visão do mundo do fotógrafo.

A configuração visual das representações pré-fotográficas de actores dos seus gestos, figurinos, adereços, poses, caracteristicas faciais, expressões, tipos de corpos, e até mesmo dos cenários nos quais são retratados, está tão relacionada com a identidade, com os motivos e com a herança iconográfica dos artistas que os retrataram, como com a verdadeira aparência, espectáculos e cenários dos actores retratados. (Katritzky 1999: 81, tradução minha)

Qualquer uma das imagens publicadas apresenta, assim, uma textura diferente, como se ao utlizador fosse dado acesso a diferentes prismas para a compreensão de cada documento: "o dilema referencial" enunciado por Balme (1997: 190) aponta a dúvida de base com a qual se depara quem questiona uma imagem de teatro - qual o equilibrio entre a realidade histórico-teatral representada e a influência do fotógrafo bem como do seu background e contexto artístico na época da captação? Não pretendemos responder, apenas sublinhar esta questão na medida em

1 "A fotografia dependia de poses cuidadosamente conservadas e no que diz respeito à interpretação, o tempo relativamente longo em que a pose tinh

que ser mantida não constituia obstáculo para a reprodução do momento teatral [...] 05

climaxes e as fortes cortinas da cena teatra do século XIX faziam isso

mesmo, exigindo dos actores a capacidade de

transmitir fisica e

graficamente 0

sentimento primordial de

uma personagem",

(Senelick 1997: 256

tradução minha). que a obra de que aqui damos conta nos parece ser reflexo de algumas destas problemáticas.

A verdade é que, quer a já referida remissão das informações para o final da obra, quer o prefácio da autoria do director do Museu Nacional do Teatro nos levam a crer que a problemática de Balme, muito embora sempre presente em qualquer icononografia teatral, parece ser sublimada em Rostos e poses. Não se tratará talvez de procurar a data exacta de produção da imagem, nem mesmo o espectáculo do qual foi retirada a personagem que veste o actor fotografado: a obra que aqui apresentamos supera claramente as questões meramente documentais (nalguns casos, bastante importantes) para apresentar os retratos pela sua "qualidade estética". Duas provas disso mesmo: em primeiro lugar, a fotografia escolhida para a capa (da qual não temos, infelizmente, nenhuma informação), dando como mote o que se considera como uma verdadeira imagem de teatro, da qual ressaltam as plumas, as lantejoulas e uma pose claramente artificial. Paralelamente, a série de fotografias de Estevão Amarante que figura mal abrimos o livro e que é pautada pela diversidade das poses e pela mímica expressiva do actor: o seu rosto assume, claramente, o papel de protagonista.

Rostos e poses ou poses dos rostos ou rostos em pose. A obra aqui compilada por José Carlos Alvarez é prova viva da complexidade da profissão de actor, numa certa altura da História, profundamente ligada à arte da fotografia que se crê, em si, e pela sua capacidade de fixar o momento, mais fácil de analisar esteticamente do que um espectáculo teatral. Rostos e poses fixa, afinal, momentos esteticamente belos duma certa amostra de iconografia teatral. Aos actores, no século XIX, início do século $X X$, era exigido um longo tempo de imobilidade para que a fotografia fosse tirada com maior qualidade ${ }^{1}$, pelo que facilmente se depreende que as imagens em causa não constituem documentos históricos de um dado espectáculo, mas sim produções quase novas, encenações de um teatro virtual. Nesta medida, podemos dizer que Rostos e poses põe este espólio de iconografia teatral no pedestal correcto - o do belo, o da estética, o da pose sem se deixar prender nas malhas da sede de objectividade dos nossos dias.

\section{Referências bibliográficas}

BALME, Christopher B. (1997), "Interpreting the Pictorial Record: Theatre Iconography and the Referential Dilemma", Theatre Research International, vol. 22, n. 3, Oxford University Press in Association with the International Federation for Theatre Research.

BALME, Christopher / ERESTEIN, Robert / MOLINARI, Cesare (eds.) (2002), European Theatre Iconography: Proceedings of the European Science Foundation Network, compil. Maria Chiara Barbieri e Sandra Pietrini, Roma, Bulzoni Editore.

BARTHES, Roland (1976), Mitologias, trad. e pref. José Augusto Seabra, Lisboa, Edições 70, pp.19-21.

KATRITZKY, M. A. (1999), "Performing-Arts Iconography: Traditions, Techniques, and Trends", Picturing Performance: The Iconography of the Performing Arts in Concept and Practice, Rochester, University of Rochester Press, pp. 68-90.

MOLINARI, Cesare (2002), "Preface", European Theatre Iconography: Proceedings of the European Science Foundation Network, ed. Christopher Balme et al. (2002), pp.11-20.

SENELICK, Laurence (1997), "Early Photographic Attempts to Record Performance Sequence", Theatre Research International, vol. 22, n. 3 , Oxford University Press in Association with the International Federation for Theatre Research.

-- (2002), "Theatricality Before the Camera: The Earliest Photographs of Actors", BALME et al. (2002). 